\title{
Comparison of outcomes between primary and secondary lung decortication
}

\author{
Joseph Motshedi Sekgololo, Risenga Frank Chauke
}

Cardiothoracic Surgery Department, Sefako Makgatho Health Sciences University, Pretoria, South Africa

Contributions: (I) Conception and design: JM Sekgololo; (II) Administrative support: All authors; (III) Provision of study materials or patients: JM Sekgololo; (IV) Collection and assembly of data: All authors; (V) Data analysis and interpretation: All authors; (VI) Manuscript writing: All authors; (VII) Final approval of manuscript: All authors.

Correspondence to: Dr. Joseph Motshedi Sekgololo. Cardiothoracic Surgery Department, Sefako Makgatho Health Sciences University, P.O Box 124, Medunsa, 0204, Pretoria, South Africa. Email: motshedi.sekgololo@gmail.com.

Background: With the view to compare the outcomes between primary and secondary lung decortication, we examined all the patients admitted with empyema thoracis in our unit. The primary decortication was defined as a primary procedure, without prior attempt of pleural space evacuation with either chest tube or previous decortication. Secondary decortication was defined as a failed lung re-expansion after initial pleural space drainage or failed primary decortication. Anecdotally, secondary decortication is associated with increased complications and length of hospital stay. From literature search, there is currently no study that directly compared outcomes of these two procedures; hence, the rationale to conduct this study.

Methods: All patients presented to our unit with empyema thoracis from $1^{\text {st }}$ January $2011-31^{\text {st }}$ December 2014, were included in a retrospective quantitative descriptive study. A total number of 160 patients were analyzed and eighty patients underwent each of the procedures (primary and secondary decortication). A comparison of prospective outcomes of the two groups was made. Fisher Exact test was used to compare percentages including the rates of complications between primary and secondary decortication. Mean values were compared using the $t$-test. The frequencies of other variables were also determined.

Results: There was significant statistical difference in the length of hospital stay (ICU and Ward) and between patients who underwent primary as opposed to secondary decortication. The frequencies of complications (chest wall abscess, recurrent empyema, wound sepsis and wound dehiscence) were higher for secondary decortication, but without statistical significance. There was significant statistical difference in terms of age, CD4 count (only for HIV patients) and Adenosine deaminase (ADA) between patients who underwent primary instead of secondary decortication.

Conclusions: The patient who underwent secondary lung decortication had a more prolonged hospital stay than those who had primary decortication. There were increased frequencies of complication in secondary decortication group, though without statistical significant difference $(\mathrm{P}=0.456)$. The patients who underwent secondary decortication had poor nutritional state compared to those who had primary decortication, with significant statistical difference $(\mathrm{P}=0.0370)$.

Keywords: Decortication; empyema thoracis; complications; outcomes

Submitted Oct 12, 2019. Accepted for publication Dec 10, 2019.

doi: $10.21037 /$ jtd.2019.12.135

View this article at: http://dx.doi.org/10.21037/jtd.2019.12.135 


\section{Introduction}

Lung decortication is commonly done for the patients with empyema thoracis and associated lung entrapment at our unit. Primary decortication is when decortication is a primary procedure; without a prior attempt of pleural space evacuation either by chest tube or previous decortication (1). Secondary decortication is decortication following a failed full lung re-expansion after initial pleural space drainage or after failed primary decortication (1). Empyema thoracis is pus in the pleural space. It has three stages: stage I (exudative), stage II (fibrinopurulent), stage III (organized). The choice of initial intervention for empyema thoracis depends on its stage. The appropriate patient selection reduces and prevents patient from undergoing secondary procedure such as secondary decortication. There is currently no study, which compared primary and secondary decortications and their outcomes; hence this is an interesting study. This study will help to improve patient selection for the particular procedure, which will translate to reduced morbidity and hospital costs.

\section{Methods}

The study is retrospective quantitative descriptive type. The study population included all the patients seen at our unit with empyema thoracis from $1^{\text {st }}$ January 2011-31 $1^{\text {st }}$ December 2014. We included patients with either primary or secondary empyema thoracis with or without HIV and poor nutrition as comorbidities. We excluded patients with empyema thoracis secondary to infected pleural effusion due to congestive heart failure, post lung resection empyema thoracis and malignant related empyema thoracis. From practical experience in our department it was estimated that complications occur in approximately $10 \%$ of primary and $40 \%$ of secondary decortication. We therefore obtained sample size based on the comparison of complications in the patients underwent primary versus secondary decortication. A fisher exact test with a 0.05 (5\%) two-sided significance level had $98 \%$ power to detect the difference between a rate of $0.10(10 \%)$ in patients with primary decortication versus a rate of $0.4(40 \%)$ in the patients with secondary decortications, the sample size in each group was 80 patients. Sample size estimation was made on nQuery Advisor, Release 7.0. Data was collected over 4-year period, from January 2011-December 2014. From each year, 40 flies were withdrawn: 20 for patients with primary decortication and 20 for patients with secondary decortication. A combination of sequential and random sampling was used. The following procedure was used: all files were placed in the sequential date order. Files were withdrawn randomly (blind folded) one by one. If it was for patient with primary decortication, random sampling was continued until a file was found for secondary decortication. In that manner 20 patients' files for secondary decortication were sampled from each year (a total of 40 files each year) in total sample size for the study was 160 patients.

\section{Statistical analysis}

On data analysis demographic characteristic of the patient was summarized descriptively. Continuous variables were summarized by mean, standard deviation, median interquartile range, minimum and maximum values. All categorical variables were summarized by frequency counts and percentage calculations. The Fisher Exact test was used for comparisons of percentages, including the rates of occurrence of complications, between patients post-primary and secondary decortication, and 95\% confidence interval was calculated for the difference between percentages. Mean values were compared by the $t$-test. Median values were compared by the non-parametric Wilcoxon rank sum test. All statistical tests were two sided and with a significant $\mathrm{P}$ value of 0.05 (5\%).

\section{Results}

There was significant statistical difference in length of hospital stay (ICU and Ward) between patients who underwent primary $v s$. secondary decortication as shown on (Figure 1). The primary decortication and secondary mean (standard deviation) values for days spent in ICU were 1.98 and 2.41 days respectively, with $\mathrm{P}=0.0001$. The mean values for days in the ward were 2.84 for primary decortication and 3.35 for secondary decortication, with $\mathrm{P}=0.0006$. The profiles of complications of the two groups did not differ significantly, with the $\mathrm{P}=0.456$ determined by Fisher Exact test (Figure 2). There was statistical difference in terms of age, CD4 count (only for HIV positive patients) and Adenosine deaminase (ADA) between patients who underwent primary versus secondary decortication as shown on Tables 1-3 respectively. The median values for age of primary and secondary decortication were: 37 and 30 respectively (Table 1 ), which had significant statistical difference with $\mathrm{P}=0.036$. Normality of the underlying distributions, which, was an assumption for the test could only be substantiated for both primary and secondary decortication using Shapiro-Wilk test. The 


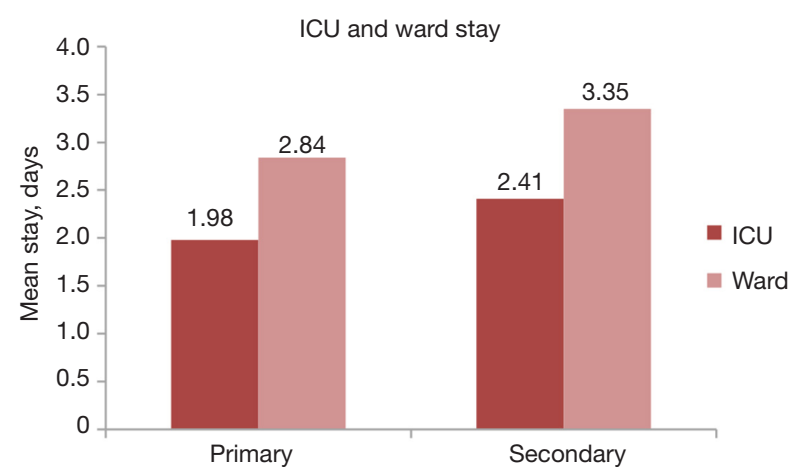

Figure 1 Means for number of days stayed in ICU and Ward for primary and secondary decortication.

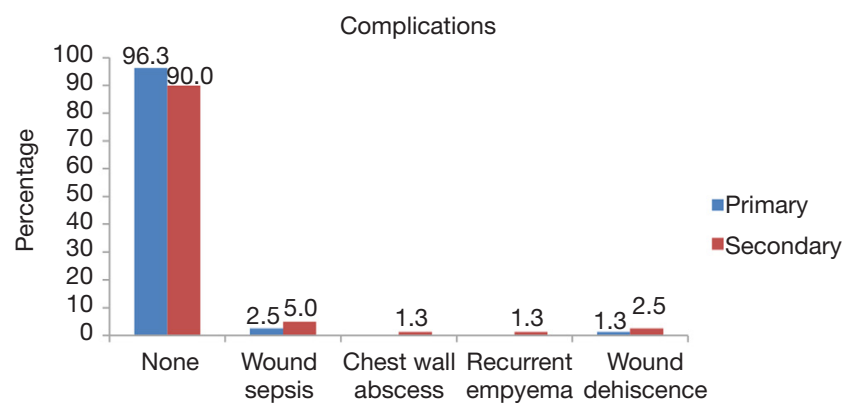

Figure 2 Complications percentages of primary and secondary decortication.

mean and median CD4 counts for the two groups differed significantly (Table 2). The $\mathrm{P}$ value for the $t$-test $(\mathrm{P}=0.035)$ was preferred in that case. The mean and median values for ADA also differed significantly (Table 3). The Wilcox rank sum test $\mathrm{P}=0.031$ was preferred (Table 3). The patient who underwent secondary decortication had poor nutritional state compared to those who had primary decortication (Figure 3), which could also have contributed to poor outcome in secondary decortications. The $\mathrm{P}$ value of both groups was $\mathrm{P}=0.0370$, which was statistically significant.

\section{Discussion}

Decortication is a surgical procedure, which involves a peeling off of restrictive fibrous layer that overlies and entraps the lung $(2,3)$. It can be undertaken via thoracotomy or video-assisted thoracoscopic surgery (VATS). In our case all 160 patients were operated via a muscle-sparing posterolateral thoracotomy in both groups. About $40 \%$ of patients with empyema thoracis will require primary decortication as a first procedure and on follow-up $1 \%$ of these patients will require secondary decortication (1).

Our study demonstrated that rather than complications demonstrated on Figure 2, with no statistical significant difference, the reasons for secondary decortication were inadequate primary procedure. The recurrent empyema thoracis was presumed to be the common reason for secondary decortication, however, in our study, the primary decortication resulted with zero percent of recurrent empyema thoracis as a complication (Figure 2). This implies that proper stage evaluation is important for the choice of the procedure.

Empyema thoracis is divided into three stages: stage I (exudative), which is rich in proteins and neutrophils with sterile serous fluid. It lasts up to two weeks, but can vary from patient to patient depending on etiology and patient's immune system $(1,4)$. Stage I is largely managed via thoracentesis or chest tube drainage with a cure rate of $90 \%$. At this stage, less than $10 \%$ patient will require secondary decortication (1). It is important to manage this stage adequately to prevent adverse outcomes that may be associated with secondary decortication such as prolonged hospital stay and complications as found in our study.

Stage II (fibrinopurulent) occurs between first and sixth week, with little or no free flowing fluid. The effusion is loculated in this stage with fibrinous materials. VATS or open decortication can manage stage II adequately (5). A drain alone will inadequately manage this stage. In one study a simple drainage (primary procedure) alone was strong a predictor for the failure in management of stage II $(1,3)$.

Stage III (organized) consist of thick fibrotic peel with little or no free flowing fluid and occurs after fifth week but period may vary (6). Its management is accomplished through VATS or open decortication. There is no room for thoracentesis, thoracostomy tube and fibrinolytics in this stage. Otherwise inadequate management with any of these procedures risks the patients for secondary decortication. Thoracotomy remains a mainstay for the treatment of organized empyema (7). Complete decortication with full lung re-expansion is a goal in stage III.

Some studies compared VATS and open decortication in the treatment of empyema thoracis and VATS was found to decrease post-operative pain, length of hospital stay and postoperative complications (4). However, in our cases, VATS was not employed. Poor nutritional status described by albumin of $<30 \mathrm{~g} / \mathrm{d}$ and immune suppression due to HIV with low CD4 count of less than 200 cells/cu.mm were found to be associated with complications, which prolonged hospital stay (8). In our study, more patients who underwent secondary decortication had unsatisfactory nutrition $(<30 \mathrm{~g} / \mathrm{d})$, which 
Table 1 The table shows statistical difference in terms of age, between primary and secondary decortication

\begin{tabular}{|c|c|c|c|}
\hline Parameter & Primary & Secondary & $P$ value \\
\hline Mean $( \pm S D)$ & $38.2( \pm 11.93)$ & $34.8( \pm 13.67)$ & $0.090^{*}$ \\
\hline Median [IQR] & 37 [29-47] & 30 [25-45] & $0.036^{* *}$ \\
\hline Min/Max & $52.00 / 800$ & $37.00 / 700$ & \\
\hline
\end{tabular}

*, student two-sample $t$-test; ${ }^{* \star}$, non-parametric Wilcoxon rank test.

Table 2 The table shows statistical significance difference between primary and Secondary decortication in terms of CD4 count

\begin{tabular}{llll}
\hline Parameter & Primary & Secondary & P value \\
\hline $\mathrm{N}$ & 80 & 80 & $0.035^{\star}$ \\
Mean $( \pm \mathrm{SD})$ & $465.8( \pm 215.78)$ & $342.22( \pm 150.66)$ & $0.041^{\star \star}$ \\
Median $(\mathrm{IQR})$ & $500(237.00-650.00)$ & $301.00(201.00-440.00)$ & $37.00 / 700$ \\
Min/Max & $52.00 / 800$ & & \\
\hline
\end{tabular}

*, student two-sample $t$-test; **, non-parametric rank sum test.

Table 3 The table shows statistical significance difference between primary and secondary decortication in terms of ADA

\begin{tabular}{llll}
\hline Parameter & Primary & Secondary & P value \\
\hline $\mathrm{N}$ & 80 & 80 & $0.045^{\star}$ \\
Mean $( \pm \mathrm{SD})$ & $50.65( \pm 15.62)$ & $57.08( \pm 22.87)$ & $0.031^{\star *}$ \\
Median $(\mathrm{IQR})$ & $49.00(40.00-57.00)$ & $56.00(43.50-63.00)$ & $28.00 / 178$ \\
Min/Max & $30.00 / 106$ & & \\
\hline
\end{tabular}

*, non-parametric Wilcoxon sum test; ${ }^{\star *}$, Student two-sample $t$-test.

could have contributed to poor outcomes (Figure 3).

Older patients underwent primary procedure more common than the younger once, which could be as a result of good insight and willingness to seek early medical help (Table 1). The patients who underwent primary procedure were willing to do HIV test, hence, majority were also willing to have a definitive procedure rather than a diagnostic one (Table 1). ADAs were determined in patients who underwent secondary procedure than those who underwent primary procedure. This is so because of the thoracenteses, which, were done in secondary decortication group (Table 3).

Empyema remains a major problem in the developing countries (9). The higher prevalence was attributed to failure to seek medical attention earlier. The secondary empyema due to clotted haemothorax is also becoming a common reason for secondary decortication in both developed and developing countries due to increased trauma $(10,11)$. Clotted haemothorax complicated with empyema thoracis should be managed adequately via decortication if it has lasted 5-7 days. Newer modalities such as intrapleural fibrinolytics have become common in management of stage II empyema thoracis (10-13). It is generally accepted that pleural empyema should be treated adequately early to avoid complications of extensive operation and long hospital stay (14).

\section{Conclusions}

The study revealed the need to stage empyema thoracis and provide appropriate initial intervention for the patients. The patients provided with inadequate procedures will require re-intervention in the form of secondary decortication, which is associated with prolonged hospital stay and complications. The prevention of secondary procedure can; therefore, save the hospital cost. 


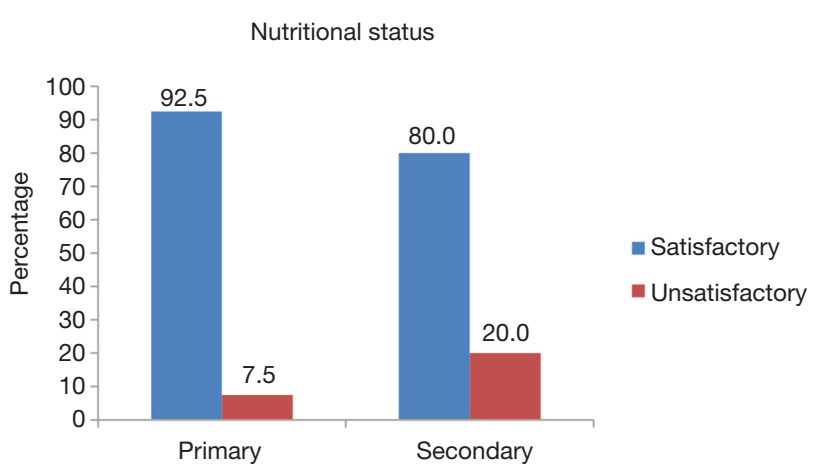

Figure 3 Percentages for nutritional status of primary and secondary decortication interpreted as satisfactory or unsatisfactory.

\section{Acknowledgments}

Dr. ME Seleka (Head of Department of Language Proficiency/English at Sefako Makgatho Health Sciences University) for assistance with language editing. Dr. PS Ramoroko (Specialist and Senior Lecturer: Department of Cardiothoracic Surgery at Sefako Makgatho Health Sciences University) for general supervision of the research group. Funding: None.

\section{Footnote}

Conflicts of Interest: The authors have no conflicts of interest to declare.

Ethical Statement: The authors are accountable for all aspects of the work in ensuring that questions related to the accuracy or integrity of any part of the work are appropriately investigated and resolved. SMUREC (Sefako Makgatho Health Science University Ethics Committee) approved protocol of this study on 04/04/2019, REF: SMUREC/M/109/20192016: J, IRB: 000010386.

Open Access Statement: This is an Open Access article distributed in accordance with the Creative Commons Attribution-NonCommercial-NoDerivs 4.0 International License (CC BY-NC-ND 4.0), which permits the noncommercial replication and distribution of the article with the strict proviso that no changes or edits are made and the original work is properly cited (including links to both the formal publication through the relevant DOI and the license). See: https://creativecommons.org/licenses/by-nc-nd/4.0/.

\section{References}

1. Mandal AK, Thadepalli H, Mandal AK, et al. Outcome of primary empyema thoracis: therapeutic and microbiologic aspects. Ann Thorac Surg 1998;66:1782-6.

2. Tenconi S, Waller DA. Empyema thoracis. Surgery (Oxford) 2014;32:236-41.

3. Rizvi SIA, Waller DA. Empyema Thoracic. Surgery 2011;29:217-20.

4. Hofmann HS. Modern management of empyema thoracis. Semin Thorac Cardiovasc Surg 2013;25:287-91.

5. Chan DT, Sihoe AD, Chan S, et al. Surgical treatment for empyema thoracis: is video-assisted thoracic surgery "better" than thoracotomy?. Ann Thorac Surg 2007;84:225-31.

6. Taylor MD, Kozower BD. Surgical spectrum in the management of empyemas. Thorac Surg Clin 2012;22:431-40.

7. Wozniak CJ, Paull DE, Moezzi JE, et al. Choice of first intervention is related to outcomes in the management of empyema. Ann Thorac Surg 2009;87:1525-30; discussion 1530-1.

8. Shields TW, Locicero L, Ponn RB, et al. General Thoracic Surgery. Lippincott Williams and Wilkins; 2005.

9. Malhotra P, Aggarwal AN, Agarwal R, et al. Clinical characteristics and outcomes of empyema thoracis in 117 patients: a comparative analysis of tuberculous vs. non-tuberculous aetiologies. Respir Med 2007;101:423-30.

10. Miller JI. Empyema thoracis. Ann Thorac Surg 1990;50:343-4.

11. Ali I, Unruh H. Management of empyema thoracis. Ann Thorac Surg 1990;50:355-9.

12. Light RW. Parapneumonic effusions and empyema. Proc Am Thorac Soc 2006;3:75-80.

13. Maskell NA. Davies CWH. Nuun AJ, et al. U.K Controlled trial of Intrapleural Streptokinase for pleural effusion. N Engl J Med 2005;352:865-74.

14. Soriano T, Alegre J, Alemán C, et al. Factors influencing length of hospital stay in patients with bacterial pleural effusion. Respiration 2005;72:587-93.

Cite this article as: Sekgololo JM, Chauke RF. Comparison of outcomes between primary and secondary lung decortication. J Thorac Dis 2020;12(3):568-572. doi: 10.21037/jtd.2019.12.135 